\title{
Lipoma pediculado endoluminal gigante del esófago*
}

\author{
Drs. FERNANDO BARRIENTOS C. ${ }^{1}$, CARLOS AYALA P. ${ }^{2}$, \\ VERÓNICA FONSECA S. ${ }^{1}$, WALTERIO MUÑOZ C. ${ }^{1}$, HERNÁN HERRERA C. ${ }^{3}$ \\ 1 Servicio de Cirugía, Hospital Hernán Henríquez Aravena. \\ 2 Interno de Medicina, Universidad de La Frontera. \\ 3 Residente de Cirugía, Universidad de La Frontera. \\ Temuco, Chile.
}

\section{Giant endoluminal pedunculated lipoma originating in the esophagus}

Paciente varón, 50 años, ingresa a hospital Hernán Henríquez Aravena de Temuco por cuadro de disfagia intermitente, disnea de esfuerzo, tos y expectoración mucopurulenta. Se realiza Tomografía Computada (TC), tránsito baritado esofágico y esofagoscopia donde se observa en pared posterior del esófago solevantamiento desde los $17 \mathrm{~cm}$ con oclusión completa a los $23 \mathrm{~cm}$, diagnosticándose tumor lipomatoso submucoso de esófago cervical. Se procede a la resección quirúrgica del tumor, extrayéndose tejido que al corte presenta aspecto adiposo, color amarillento, de consistencia blanda. Anatomopatológicamente se diagnostica lipoma en pared de tipo esofágico. Evoluciona sin problemas relacionados al procedimiento quirúrgico.

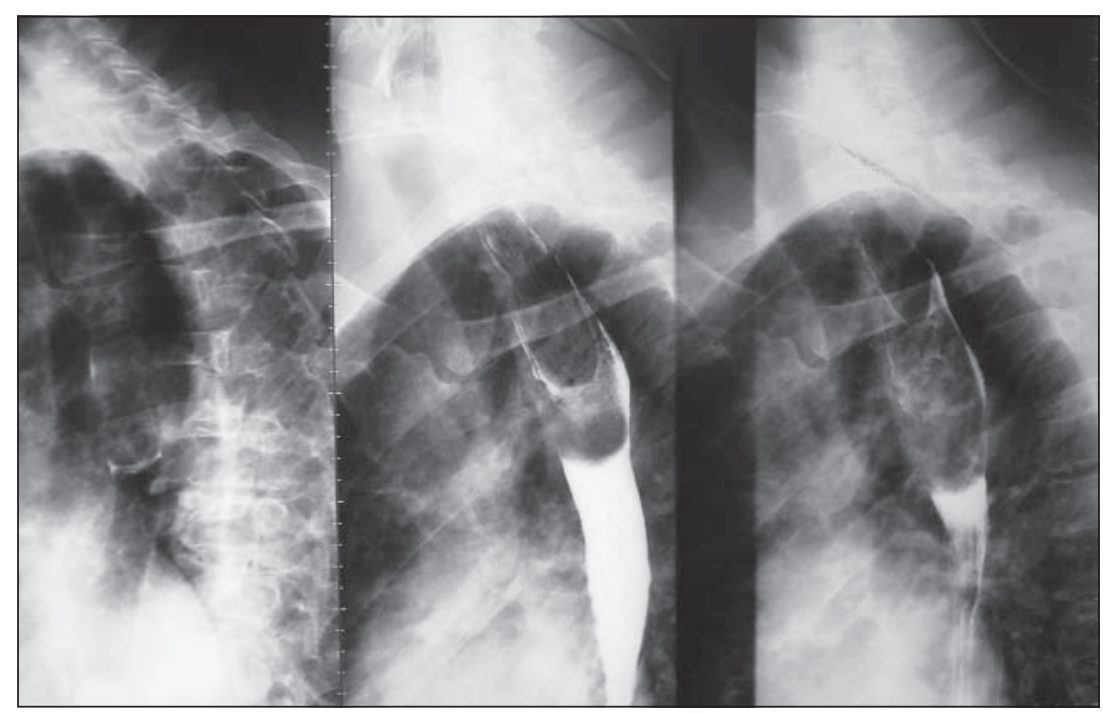

Figura 1. Tránsito baritado esofágico. Pólipo ovalado en mitad superior del esófago cuyo pedículo parece insertarse en la unión entre esófago cervical y torácico.

*Recibido el 2 de agosto de 2011 y aceptado para publicación el 11 de noviembre de 2011.

Correspondencia: Dr. Carlos Ayala P. Freire \#630, Dpto 31, Temuco, Chile. carlos_patricio911@hotmail.com 

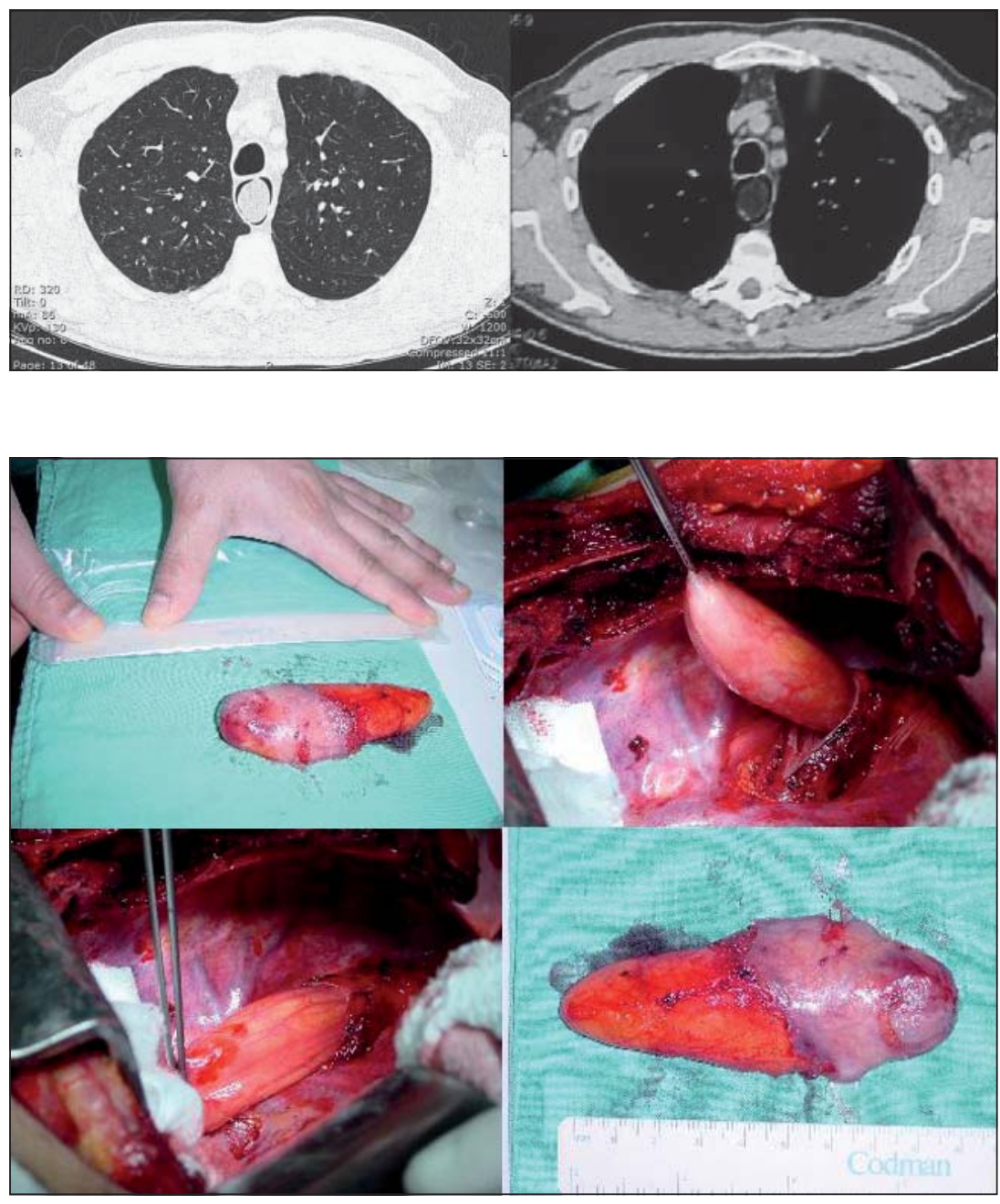

Figura 2. Tomografía Computada de Tórax. Imagen de formación polipoidea intraesofágica.
Figura 3. Cirugía: Lipoma esofágico gigante exteriorizado, de aspecto adiposo, de $8,5 \mathrm{~cm}$ de longitud por $3 \mathrm{~cm}$ de diámetro, superficie externa lisa, brillante, pardo amarillenta.
El lipoma esofágico constituye una patología rara, habiéndose reportado hasta 2005 sólo 20 casos de lipomas esofágicos resecados ${ }^{1,2}$. Son habitualmente pequeños y asintomáticos. Ocasionalmente, se elongan, pediculan y ocupan el espacio endoluminal, habiéndose descrito casos de obstrucción aguda de la vía aérea por migración del tumor ${ }^{3,4}$.

Su diagnóstico se realiza mediante exámenes endoscópicos y radiológicos habituales².

Se recomienda una conducta expectante con controles seriados en caso de lipomas pequeños y asintomáticos ${ }^{2}$. La escisión está indicada para prevenir la obstrucción laríngea aguda ${ }^{4}$; puede realizarse por vía endoscópica o cirugía abierta según el tamaño del lipoma ${ }^{2}$.

\section{Referencias}

1. Wang Chien-Ying, Hsu Han-Shui, Wu Yu-Chung, Huang Min-Hsiung, Hsu Wen-Hu. Intramural lipoma of the esophagus. J Chin Med Assoc. 2005;68:5.

2. Castro-Boix S, Nadal-Guinard A. Lipoma esofágico gigante. Cir Esp. 2006;80:337-8.

3. Samad L, Ali M, Ramzi H, Akbani Y. Respiratory distress in a child caused by lipoma of the esophagus. J Pediatr Surg. 1999;34:1537-8.

4. Hasan N, Madani P. Respiratory obstruction caused by lipoma of the esophagus. J Pediatr Surg. 1994;29:15656. 